Pacific Journal of Mathematics

THE SIMPLICITY OF CERTAIN GROUPS 


\section{THE SIMPLICITY OF CERTAIN GROUPS}

\section{ROBERT SteINBERG}

The purpose of this note is to give a proof of the simplicity of certain "Lie groups" considered in [2]. The main feature of the present development is the proof of Lemma 2 below: it is superior to the corresponding proof given in [2], because no assumption on the number of elements of the base field is required, and is very much shorter than the one given by Chevalley [1] for the direct analogues, over arbitrary fields, of the simple (complex) Lie groups. Thus it turns out that the groups $E_{6}^{1}\left(q^{2}\right)$ with $q \leqq 4$, and $D_{4}^{2}\left(q^{3}\right)$ with $q \leqq 3$, to which the proof in (2) is not applicable, are simple.

Assuming the notations of [1] and [2] to be in effect, we shall prove:

1. Theorem. If $\hat{G}$ is one of the groups of type $G^{1}, G^{2}$ or $G^{3}$, defined in [2], and the rank $l$ of the corresponding Lie algebra is at least 3, then $\hat{G}$ is simple.

It will be noticed that the case $A_{2}^{1}$ is excluded by the assumption on $l$. This is of necessity, since the simplicity of $A_{2}^{1}$ is not universal, but depends on the base field. The same is true of groups of type $A_{1}$.

2. MAIN Lemma. Let $\hat{G}$ be a group of type $G$, that is, one of the direct analogues of the ordinary simple Lie groups, or a group of type $G^{1}, G^{2}$ or $G^{3}$, but assume $\hat{G}$ is not of type $A_{1}$ or $A_{2}^{1}$. Let $\hat{\mathfrak{U}}$ be the nilpotent subgroup of $\hat{G}$ corresponding to the positive roots of the underlying Lie algebra. Let $H$ be a normal subgroup of $\hat{G}$ such that $|H|>1$. Then $|H \cap \hat{\mathfrak{u}}|>1$.

Proof. Assume first that $G$ is of type $G^{1}$. By 7.2 of [2], there is $x=u h \omega(w) \in H$ with $u \in \mathfrak{U}^{1}, h \in \mathfrak{W}^{1}$.

If $w=1$, then [2, Lemma 8.5] yields the required conclusion.

If $w \neq 1$, consider first the case in which $w=w_{s}$ with $S$ a fundamental element of $\Pi^{1}$. Then there is a fundamental $A \in \Pi^{1}$ such that $B=w A>0$ and $w A \neq A$ (because $A_{1}$ and $A_{2}^{1}$ are excluded). Choose $y \in \mathfrak{U}_{A}^{1}$ so that $y \neq 1$ and $y \notin \mathfrak{U}_{2}$, the subgroup of $\mathfrak{u}$ generated by those $\mathfrak{X}_{r}$ for which $h t r \geqq 2$. Then we assert that the commutator $z=(x, y)$ is in $H \cap \mathfrak{u}^{1}$ and that $z \neq 1$. In fact, $z=u h \omega(w) y \omega(w)^{-1} h^{-1} u^{-1} y^{-1}=u t u^{-1} y^{-1}$ with $t \in \mathfrak{H}_{B}^{1}$; hence $z \in H \cap \mathfrak{U}^{1}$, and, since $\mathfrak{U} / \mathfrak{H}_{2}$ is Abelian, we have $z \equiv$ $t y^{-1} \not \equiv 1 \bmod \mathfrak{U}_{2}$, by 4.3 of [2], whence $z \neq 1$.

Finally, consider the general case in which $w \neq 1$. Choose $R \in \Pi^{1}$

Received July 31, 1959. 
so that $-w R=S$ is fundamental in $\Pi^{1}$, and then $y \in \mathfrak{U}_{s}^{1}$ so that $y \neq 1$. Again form $z=(x, y)$. In the present case, $\omega(w) y \omega(w)^{-1} \in \mathfrak{u}_{s}^{1} \mathfrak{l}^{1} \omega\left(w_{s}\right) \mathfrak{u}_{s}^{1}$ by 7.3 of [2], so that $z$ is conjugate to an element $x_{1}$ of the form $u_{1} h_{1} \omega\left(w_{s}\right)$ with $u_{1} \in \mathfrak{U}^{1}, h_{1} \in \mathfrak{S}^{1}$. Clearly $x_{1} \neq 1$ and $x_{1} \in H$. Thus the situation is that at the beginning of the preceding paragraph, and Lemma 2 is proved for groups of type $G^{1}$.

Now to get a proof for groups of type other than $G^{1}$, we need only delete all superscripts or replace them all by 2 or all by 3 , depending on the group under consideration.

From this point on, we assume that $\hat{G}$ is of type $G^{1}$, but not of type $A_{l}^{1}$ ( $l$ even), and the ensuing discussion refers explicitely to this case. For groups of type $A_{l}^{1}$ ( $l$ even), $G^{2}$ or $G^{3}$, the changes to be made are quite clear: a prototype for these changes is the replacement of $\left(^{*}\right)$ below by an appropriate analogue. For groups of type $G$, the rest of the proof of Theorem 1 is given in [1].

3. Lemma. If $G^{1}$ is not of type $A_{l}^{1}(l$ even) and $H$ is a normal subgroup of $G^{1}$ such that $|H|>1$, then, for some $R \in \Pi^{1},\left|H \cap \mathfrak{U}_{R}^{1}\right|>1$.

It is convenient to precede the proof of this lemma by some preparatory results.

4. Lemma. If $s, a, s+a$ and $t$ are roots such that $\bar{a} \neq a$ and $s+a=t+\bar{a}$, then $t=\bar{s}$.

Proof. We have $s(a)<0$ and $s(\bar{a})=(s+a)(\bar{a})>0$. Hence $\bar{s} \neq s$, and a simple calculation shows that $t-\bar{s}=s+a-\bar{s}-\bar{a}$ has length 0 , since all roots have the same length and the only possible angles are the multiples of $\pi / 3$ and $\pi / 2$. Hence $t=\bar{s}$.

Let us recall that, for each positive integer $m, \mathfrak{u}_{m}$ denotes the subgroup of $\mathfrak{U}$ generated by those $\mathfrak{X}_{r}$ for which $h t r \geqq m$.

5. Lemma. Let $s$ be a positive root, a a fundamental root, and $S$ and $A$ the elements of $\Pi^{1}$ which contain them. Assume $s(a)<0$, $x \in \mathfrak{U}_{s}^{1}, y \in \mathfrak{U}_{A}^{1}$, and set $h t s=n$. Then

(a) $(x, y)$ is congruent, $\bmod \mathfrak{U}_{n+2}$, to an element of $\mathfrak{u}^{1}$ whose representation 4.3 of [2] has all components other than those from $\mathfrak{X}_{s+a}$ and $\mathfrak{X}_{\bar{s}+\bar{a}}$ equal to 1 , and

(b) if $x$ is given and $x \neq 1$, then $y$ can be chosen so that the $\mathfrak{X}_{s+a}$ component is not 1.

Proof. Assume first $|S|=|A|=2$. Then $(s, a)<0$, whence $(s, \bar{a}) \geqq 0$, because the contrary assumption yields the false conclusion that $s+\bar{s}+a+\bar{a}$ has length 0 . Thus $\mathfrak{X}_{s}$ and $\mathfrak{X}_{a}$ commute elementwise with $\mathfrak{X}_{\bar{s}}$ and $\mathfrak{X}_{\bar{a}}$, and 4.1 of [2] yields 


$$
\left(x_{s}(k) x_{\bar{s}}(\bar{k}), x_{a}(l) x_{\bar{a}}(\bar{l})\right)=x_{s+a}\left(N_{s a} l l\right) x_{\bar{s}+\bar{a}}\left(N_{s a} \bar{k} \bar{l}\right) .
$$

Thus (a) is true. If $k \neq 0$, we can choose $l$ so that $k l+\bar{k} l \neq 0$, and then coalesce the terms on the right of $\left(^{*}\right)$ if $\bar{s}+\bar{a}=s+a$. Thus (b) is also true. If $|S|=1$ or $|A|=1$, we replace $\left({ }^{*}\right)$ in the above argument by an appropriate analogue (see 4.1 and 8.8 of [2]).

Let us recall that a root $d$ is dominant if $d(a) \geqq 0$ for each fundamental root $a$. Since these inequalities define a fundamental region for $W$, and all roots are congruent under $W$ in the present case, it follows that there is a unique dominant root $d$. If $s$ is any other root, then $(s, a)<0$ for some fundamental root $a$, and then $s+a$ is also a root. Thus the dominant root $d$ may also be described as the unique root of maximum height; and one has $\bar{d}=d$ and $d>s$ for each root $s \neq d$.

We now turn to the proof of Lemma 3. Among all $x \in H \cap \mathfrak{u}^{1}$ for which $x \neq 1$, choose one which maximizes the minimum $S \in I^{1}$ for which $x_{S} \neq 1$ in the representation 4.5 of [2]. If this minimum is $R$, we show $x=x_{R}$. Assuming the contrary, one can write $x=x_{R} x_{T} \cdots$ with $x_{T} \neq 1$. Set $h t R=n$. If $r \in R$, then $r$ is not dominant, since $R<T$. Thus $r(a)<0$ for some fundamental root $a$, and $r+a$ is a root. If $a \in A \in \Pi^{1}$, we conclude from Lemma 5 that there is $y \in \mathfrak{U}_{A}^{1}$ such that $\left(x_{R}, y\right)$ is congruent, $\bmod \mathfrak{U}_{n+2}$, to an element of $\mathfrak{u}^{1}$ with the $\mathfrak{X}_{r+a}$ component not 1 . Since $z=(x, y) \in H \cap \mathfrak{U}_{n+1}$, and $>$ respects heights, we need only show $z \neq 1$ to reach a contradiction. We have $(x, y)=\left(x_{R}, y\right)\left(x_{T}, y\right) \cdots \bmod \mathfrak{u}_{n+2}$. Here the elements on the right are in $\mathfrak{u}_{n+1}$. By choice of $y$, the $\mathfrak{X}_{r+a}$ component of $\left(x_{R}, y\right)$ is not 1 , and by Lemmas 4 and 5 , the $\mathfrak{X}_{r+a}$ component of each of $\left(x_{r}, y\right) \cdots$ is 1 . Thus we conclude from 4.3 of [2] and the fact that $\mathfrak{U}_{n+1} / \mathfrak{U}_{n+2}$ is Abelian that $(x, y) \not \equiv 1 \bmod \mathfrak{U}_{n+2}$. Therefore $(x, y) \neq 1$, and Lemma 3 is proved.

The proof of Theorem 1 can now be completed, just as in [2].

\section{REFERENCES}

1. C. Chevalley, Sur certains groupes simples, Tôhoku Math. J. (2) 7 (1955), p. 14.

2. R. Steinberg, Variations on a theme of Chevalley, Pacific J. Math. 9 (1959), p. 875. 



\section{PACIFIC JOURNAL OF MATHEMATICS}

\section{EDITORS}

\author{
David Gilbarg \\ Stanford University \\ Stanford, California \\ F. H. Brownell \\ University of Washington \\ Seattle 5 , Washington
}

\author{
A. L. Whiteman \\ University of Southern California \\ Los Angeles 7, California \\ L. J. PAIGE \\ University of California \\ Los Angeles 24, California
}

\section{ASSOCIATE EDITORS}

\author{
E. F. BECKENBACH \\ T. M. CHERRY \\ D. DERRY
}
E. HEWITT
A. HORN
L. NACHBIN
M. OHTSUKA
H. L. ROYDEN
M. M. SCHIFFER

E. SPANIER

E. G. STRAUS

F. WOLF

\section{SUPPORTING INSTITUTIONS}

\author{
UNIVERSITY OF BRITISH COLUMBIA \\ CALIFORNIA INSTITUTE OF TECHNOLOGY \\ UNIVERSITY OF CALIFORNIA \\ MONTANA STATE UNIVERSITY \\ UNIVERSITY OF NEVADA \\ NEW MEXICO STATE UNIVERSITY \\ OREGON STATE COLLEGE \\ UNIVERSITY OF OREGON \\ OSAKA UNIVERSITY \\ UNIVERSITY OF SOUTHERN CALIFORNIA
}

\author{
STANFORD UNIVERSITY \\ UNIVERSITY OF TOKYO \\ UNIVERSITY OF UTAH \\ WASHINGTON STATE COLLEGE \\ UNIVERSITY OF WASHINGTON

AMERICAN MATHEMATICAL SOCIETY
CALIFORNIA RESEARCH CORPORATION
HUGHES AIRCRAFT COMPANY
SPACE TECHNOLOGY LABORATORIES
NAVAL ORDNANCE TEST STATION

Mathematical papers intended for publication in the Pacific Journal of Mathematics should be typewritten (double spaced), and the author should keep a complete copy. Manuscripts may be sent to any one of the four editors. All other communications to the editors should be addressed to the managing editor, L. J. Paige at the University of California, Los Angeles 24, California. ..

50 reprints per author of each article are furnished free of charge; additional copies may be obtained at cost in multiples of 50 .

The Pacific Journal of Mathematics is published quarterly, in March, June, September, and December. The price per volume (4 numbers) is $\$ 12.00$; single issues, $\$ 3.50$. Back numbers are available. Special price to individual faculty members of supporting institutions and to individual members of the American Mathematical Society: $\$ 4.00$ per volume; single issues, $\$ 1.25$.

Subscriptions, orders for back numbers, and changes of address should be sent to Pacific Journal of Mathematics, 2120 Oxford Street, Berkeley 4, California.

Printed at Kokusai Bunken Insatsusha (International Academic Printing Co., Ltd.), No. $6_{4}$ 2-chome, Fujimi-cho, Chiyoda-ku, Tokyo, Japan.

PUBLISHED BY PACIFIC JOURNAL OF MATHEMATICS, A NON-PROFIT CORPORATION

The Supporting Institutions listed above contribute to the cost of publication of this Journăl, but they are not owners or publishers and have no responsibility for its content or policies. 


\section{Pacific Journal of Mathematics}

\section{Vol. 10, No. $3 \quad$ November, 1960}

Glen Earl Baxter, An analytic problem whose solution follows from a simple

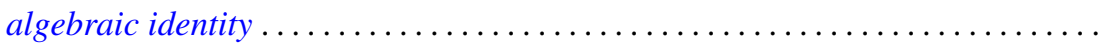

Leonard D. Berkovitz and Melvin Dresher, A multimove infinite game with linear payoff. .

Earl Robert Berkson, Sequel to a paper of A. E. Taylor ......................

Gerald Berman and Robert Jerome Silverman, Embedding of algebraic systems.... 767

Peter Crawley, Lattices whose congruences form a boolean algebra . . . . . ...... 777

Robert E. Edwards, Integral bases in inductive limit spaces . . . . . . . . . . . . . . .

Daniel T. Finkbeiner, II, Irreducible congruence relations on lattices . . . . . . . . . .

William James Firey, Isoperimetric ratios of Reuleaux polygons . . . . . . . . . . . 787



Leon W. Green, A sphere characterization related to Blaschke's conjecture........

Israel (Yitzchak) Nathan Herstein and Erwin Kleinfeld, Lie mappings in

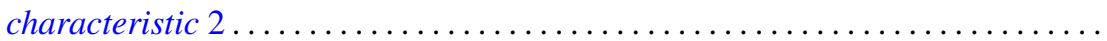

Charles Ray Hobby, A characteristic subgroup of a $p$-group .................

R. K. Juberg, On the Dirichlet problem for certain higher order parabolic

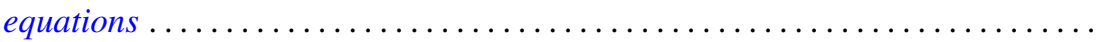

Melvin Katz, Infinitely repeatable games ......................

Emma Lehmer, On Jacobi functions . . . . . . . . . . . . . . . . . . . . . . . . .

D. H. Lehmer, Power character matrices

Henry B. Mann, A refinement of the fundamental theorem on the density of the sum of two sets of integers.

Marvin David Marcus and Roy Westwick, Linear maps on skew symmetric matrices: the invariance of elementary symmetric functions . .

Richard Dean Mayer and Richard Scott Pierce, Boolean algebras with ordered

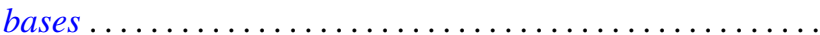

Trevor James McMinn, On the line segments of a convex surface in $E_{3} \ldots$

Frank Albert Raymond, The end point compactification of manifolds ..

Edgar Reich and S. E. Warschawski, On canonical conformal maps of regions of arbitrary connectivity

Marvin Rosenblum, The absolute continuity of Toeplitz's matrices...

Lee Albert Rubel, Maximal means and Tauberian theorems . .

Helmut Heinrich Schaefer, Some spectral properties of positive linear operators

Jeremiah Milton Stark, Minimum problems in the theory of pseudo-conformal transformations and their application to estimation of the curvature of the invariant metric.

Robert Steinberg, The simplicity of certain groups ...

Hisahiro Tamano, On paracompactness. .

Angus E. Taylor, Mittag-Leffler expansions and spectral theory .

Marion Franklin Tinsley, Permanents of cyclic matrices ...... . 